УДК 543.51-543.54

\title{
ХИМИЧЕСКИЙ СОСТАВ ЛИПИДОВ ЛИСТОСТЕБЕЛЬНЫХ МХОВ - ТОРФООБРАЗОВАТЕЛЕЙ ЭВТРОФНЫХ БОЛОТ ЗАПАДНОЙ СИБИРИ
}

\section{И АЛТАЯ}

(C) О.В. Серебренникова ${ }^{1,2}$, Е.Б. Стрельникова ${ }^{1}$, И.В. Русских ${ }^{1}$, Ю.И. Прейс ${ }^{3}$, М.А. Дучко ${ }^{1,2}$ *

${ }^{1}$ Институт химии нефрти СО РАН, пр. Академический, 4, Томск, 634055

(Россия), e-mail: maria.duchko@gmail.com

${ }^{2}$ Национальный исследовательский Томский политехнический университет, пр. Ленина, 30, Томск, 634050 (Россия)

${ }^{3}$ Институт мониторинга климатических и экологических систем СО РАН, пр. Академический, 10/3, Томск, 634055 (Россия)

Методом газовой хроматографии-масс-спектрометрии был определен молекулярный состав липидов в трех образцах листостебельных мхов (Aulacomnium palustre, Warnstorfia fluitans и Calliergon giganteum). В составе ациклических соединений были идентифицированы алканы нормального и изопреноидного строения, изопреноидные алкены, карбоновые кислоты, их эфиры, спирты, альдегиды, а также кетоны нормального и изопреноидного строения. Среди циклических соединений были обнаружены би-, три- и тетрациклические полициклоароматические углеводороды (ПАУ), бициклические и пентациклические терпеноиды, стероиды, токоферолы. Показано, что среди идентифицированных органических соединений во мхах максимально содержание карбоновых кислот и $н$-алканов, среди которых преобладает гомолог $\mathrm{C}_{27}$. Обнаружено, что A. palustre характеризуется пониженным содержанием изопреноидных соединений, спиртов, кетонов и повышенным содержанием ненасыщенных кислот, пентациклических терпеноидов и альдегидов. A. palustre также отличается от W. fluitans и $C$. giganteum составом стероидов. Среди сесквитерпеноидов в A. palustre был обнаружен эремофилен, отсутствующий в Амблистегиевых мхах. Содержание ликопадиена, карбоновых кислот, н-алканов, фит-2-ена, альдегидов, эфиров, сквалена, диплоптена, $\alpha$-токоферола и трифенилфосфатов в $W$. fluitans выше по сравнению с $C$. giganteum.

Ключевые слова: листостебельные мхи, газовая хроматография, масс-спектрометрия, $H$-алканы, кислородсодержащие органические соединения, полициклоароматические углеводороды, терпеноиды, стероиды.

Работа выполнена при частичной финансовой поддержке гранта РФФИ 15-05-03910.

\section{Введение}

На территории Западной Сибири и Алтая широко распространены различные виды мхов, являющиеся одними из основных болотных растений-торфообразователей. Торфяные экосистемы и болотная раститель-

Серебренникова Ольга Викторовна - доктор химических наук, профессор кафедры геологии и разведки полезных ископаемых, заведующая лабораторией природных превращений нефти, e-mail: ovs@ipc.tsc.ru.

Стрельникова Евгения Борисовна - кандидат

химических наук, научный сотрудник, e-mail: seb@ipc.tsc.ru

Русских Ирина Владимировна - кандидат химических наук, научный. сотрудник, e-mail: rus@ipc.tsc.ru.

Прейс Юлия Ивановна - кандидат биологических наук, старший научный сотрудник, e -mail: preisyui@imces.ru. Дучко Мария Александровна - ассистент кафедры химической технологии топлива и химической кибернетики, аспирант, e-mail: maria.duchko@gmail.com ность очень чувствительны к изменениям окружающей среды, особенно влажности и температуры [1].

Отдельные виды болотных растений имеют разный химический состав, во многом зависящий от места и условий обитания растения. Для определения вклада конкретного растения в формирование торфа и получения информации об условиях окружающей среды и структурных изменениях, происходивших с органическим веществом в ходе разложения торфа, необходимо знать состав исходной растительной биомассы. В то же время сведения

\footnotetext{
* Автор, с которым следует вести переписку.
} 
о химическом составе болотных растений весьма ограничены. О химическом составе стероидов, терпеноидов, ациклических кислородсодержащих соединений и углеводородов (УВ) в наземных растениях (шейхцерия, осока, пушица и сфагнум магелланикум) сообщалось в [2, 3], в водных растениях (рдест, рогоз и хара) - в [4].

Цель данной работы - изучение особенностей состава биомаркеров трех разновидностей листостебельных мхов.

\section{Экспериментальная часть}

В качестве объектов исследования были выбраны широко распространенные на болотах Сибири мхи семейства Амблистегиевых - Calliergon giganteum и Warnstorfia fluitans и семейства Аулакомниевых Aulacomnium palustre. Исследуемые мхи относятся к классу Листостебельные мхи (Musci).

Отбор проб мхов проводился при проведении полевых работ в период с 5 по 10 августа 2014 г. Срезались верхние зеленые части мхов длиной 3-5 см. На площади 1 м² отбиралось по 5 образцов мхов одного вида, после этого пробы усреднялись.

Образец мха C. giganteum был отобран с участка, расположенного в южной части Большого Васюганского болота, на границе южной тайги и подтайги Западной Сибири. Обследованный участок болота является сильно обводненной эвтрофной болотнотравно-осоково-гипновой топью, для которой характерны стабильно высокие уровни болотных вод. Мхи $W$. fluitans и A. palustre отобраны на территории озерноболотной системы Ештыкёль, расположенной в Горном Алтае у подножья Северо-Чуйского хребта.

Образцы мхов высушивали при комнатной температуре в течение нескольких дней и измельчали. Навеску массой 8-10 г экстрагировали 250 мл раствора 7\% метанола в хлороформе при $88{ }^{\circ} \mathrm{C}$ в течение 3 ч. Полученные экстракты упаривали на роторном испарителе, добавляли внутренний стандарт (дейтероаценафтен $\mathrm{C}_{12} \mathrm{D}_{10}$ ) и исследовали молекулярный состав органических соединений методом газовой хроматографии-масс-спектрометрии (масс-спектрометр высокого разрешения DFS, TermoElectron Finnigan DFS, Германия предоставлен центром коллективного пользования ТомЦКП СО РАН).

\section{Обсуждение результатов}

В исследованных образцах мхов были идентифицированы ациклические и циклические органические соединения. В составе ациклических соединений были зафиксированы алканы нормального и изопреноидного (пристан, фитан, 2,6,10-триметилгексадекан) строения, изопреноидные алкены (фит-2-ен, сквален, ликопа14,18-диен), насыщенные и ненасыщенные карбоновые кислоты, их метиловые, этиловые и изопропиловые эфиры, спирты (изомеры фитола), альдегиды (нонаналь и изомеры 2,4-декадиен-1-аля), а также кетоны нормального и изопреноидного строения. Среди циклических соединений были обнаружены би-, три- и тетрациклические полициклоароматические углеводороды (ПАУ), бициклические и пентациклические (производные гопана, олеана и урсана) терпеноиды, стероиды (производные холестана, эргостана, стигмастана и циклоартана), токоферолы и другие кислород- и серосодержащие органические соединения с несколькими функциональными группами. Суммарные концентрации этих соединений представлены в таблице.

В составе ациклических УВ значительно преобладают $н$-алканы. Их максимальная концентрация зафиксирована в $W$. fluitans. Наряду с различием в общем содержании отдельные виды исследованных мхов характеризуются различным количеством индивидуальных $\mu$-алканов. При максимальном содержании во всех мхах $н$-алкана $\mathrm{C}_{27}$ в W. fluitans повышено содержание $\mu-\mathrm{C}_{29}$, а в C. giganteum и A. palustre $-\mu$ - $\mathrm{C}_{29}$ и $\mu-\mathrm{C}_{16}$.

Содержание изопреноидных алканов, представленных 2,6,10-триметилгексадеканом, фитаном и норфитаном (пристаном), существенно ниже, чем $\boldsymbol{\mu}$-алканов. Их доля среди УВ наиболее высока в C. giganteum.

Тетратерпеноид с двумя двойными связями в молекуле - ликопадиен, впервые обнаруженный в водорослях Botryococcus braunii [5, 6], присутствует во всех исследованных мхах в виде трех стереоизомеров. Доля этих соединений в составе ациклических УВ максимальна в C. giganteum и существенно ниже в A. palustre. Следует отметить, что отсутствуют сведения о наличие этого УВ в каких-либо других мхах. В частности, они не были обнаружены в исследованном нами ранее сфагновом мхе [2, 3]. 
Содержание органических соединений в исследованных мхах

\begin{tabular}{|c|c|c|c|}
\hline \multirow{2}{*}{ Группа соединений } & A. palustre & W. fluitans & C. giganteum \\
\hline & \multicolumn{3}{|c|}{ Содержание, мкг/г сухой массы } \\
\hline \multicolumn{4}{|c|}{ Аичиклические } \\
\hline н-Алканы & 14,17 & 29,51 & 13,92 \\
\hline 2,6,10-триметилгексадекан & 0,03 & 0,15 & 0,17 \\
\hline Пристан & 0,19 & 0,17 & 0,33 \\
\hline Фитан & 0,24 & 0,32 & 0,36 \\
\hline Фит-2-ен & 0,03 & 0,12 & 0,05 \\
\hline Ликопа-14,18-диены & 1,18 & 4,94 & 2,94 \\
\hline Сквален & 0,95 & 0,95 & 0,22 \\
\hline Карбоновые кислоты & 44,12 & 27,85 & 17,28 \\
\hline Эфиры карбоновых кислот & 4,16 & 5,54 & 2,13 \\
\hline Спирты & 2,62 & 5,6 & 5,96 \\
\hline Альдегиды & 8,57 & 2,32 & 0,56 \\
\hline Кетоны & 1,47 & 3,13 & 2,89 \\
\hline \multicolumn{4}{|c|}{ Циклические } \\
\hline Полициклоароматические углеводороды & 0,33 & 0,32 & 0,38 \\
\hline Бициклические терпеноиды & 0,27 & 0,04 & 0,25 \\
\hline Пентациклические терпеноиды & 1,94 & 0,53 & 0,44 \\
\hline Стероиды & 4,32 & 6,04 & 4,31 \\
\hline Токоферолы & 6,92 & 7,96 & 2,30 \\
\hline Трифенилфосфаты & 0,18 & 0,19 & 0,09 \\
\hline Производные фенола & 0,10 & 0,26 & 1,16 \\
\hline$\beta$-иононы & 0,03 & 0,23 & 0,10 \\
\hline Производные фурана & 0,37 & 1,99 & 1,45 \\
\hline 3-метил-2-пентадецилтиофен & 0 & 0,02 & 0,02 \\
\hline
\end{tabular}

В Амблистегиевых мхах значительно преобладают насыщенные карбоновые кислоты и их метиловые эфиры, в A. palustre содержание насыщенных и ненасыщенных кислот и их эфиров практически одинаково. Насыщенные карбоновые кислоты состава $\mathrm{C}_{6}-\mathrm{C}_{22}$ имеют два максимума в своем распределении: первый приходится на гомолог $\mathrm{C}_{9}$, а второй - на $\mathrm{C}_{14}, \mathrm{C}_{16}$ и $\mathrm{C}_{18}$, причем преобладает пальмитиновая кислота $\left(\mathrm{C}_{16}\right)$. Среди метиловых эфиров $\left(\mathrm{C}_{15}-\mathrm{C}_{31}\right)$ также доминирует эфир пальмитиновой кислоты. Этиловые и изопропиловые эфиры насыщенных карбоновых кислот представлены лишь парой соединений: $\mathrm{C}_{18}, \mathrm{C}_{20}$ и $\mathrm{C}_{15}, \mathrm{C}_{17}$ соответственно, причем в составе изопропиловых эфиров во всех исследованных мхах преобладает гомолог $\mathrm{C}_{17}$ (эфир миристиновой кислоты), а в составе этиловых - гомолог $\mathrm{C}_{18}$ (эфир пальмитиновой кислоты).

Ненасыщенные карбоновые кислоты $\left(\mathrm{C}_{16}, \mathrm{C}_{18}\right.$ и $\left.\mathrm{C}_{20}\right)$ включают соединения с одной, двумя, тремя и четырьмя двойными связями. Среди них в $W$. fluitans преобладает линолевая - $\mathrm{C}_{18}$ кислота с двумя двойными связями в молекуле, в составе метиловых эфиров также преобладает эфир этой кислоты. В образце $C$. giganteum в большем, чем линолевая кислота, количестве обнаружены моноеновая пальмитоолеиновая $\left(\mathrm{C}_{16}\right)$ и триеновая линоленовая $\left(\mathrm{C}_{18}\right)$ кислоты, а среди метиловых эфиров, как и в $W$. fluitans, доминирует эфир линолевой кислоты. A. palustre отличается значительным преобладанием ди- и триеновой кислот $\mathrm{C}_{18}-$ олеиновой и линоленовой, более чем на порядок превышающим содержание остальных соединений.

Состав $\boldsymbol{t - а л к а н - 2 - о н о в ~ л и с т о с т е б е л ь н ы х ~ м х о в ~ в к л ю ч а е т ~ в ~ с е б я ~ р я д ~ г о м о л о г о в ~} \mathrm{C}_{19}-\mathrm{C}_{31}$ с максимальной концентрацией в $A$. palustre и $C$. giganteum нечетных структур $\mathrm{C}_{25}-\mathrm{C}_{29}$ с незначительным преобладанием гомологов $\mathrm{C}_{29}$ и $\mathrm{C}_{25}$ соответственно. Во мхе $W$. fluitans резко доминирует $\mathrm{C}_{25}$, а $\mathrm{C}_{27}$ и $\mathrm{C}_{29}$ присутствуют в подчиненном количестве.

Алкан-2-оны изопреноидного строения во всех исследованных мхах представлены преимущественно гомологом $\mathrm{C}_{18}$ с незначительной примесью $\mathrm{C}_{13}$. Их содержание в 1,4-1,5 раза превышает концентрацию $н$-алкан-2-онов в $A$. palustre и $C$. giganteum, а в $W$. fluitans эти две разновидности присутствуют в равных концентрациях.

В группе альдегидов в исследованных мхах идентифицированы нонаналь и два изомера 2,4декадиеналя с резким преобладанием нонаналя в A. palustre, 2,4-декадиеналей - в $W$. fluitans и близким их невысоким содержанием в C. giganteum.

Присутствие ПАУ в химическом составе растений может быть обусловлено их накоплением из водных растворов, воздуха и почвы [7]. Бициклические ПАУ представлены в исследованных мхах нафталином, его метил-, диметил-, триметил- и тетраметилзамещенными производными, трициклические - фенантреном, его метил-, диметил- и триметилзамещенными, а тетрациклические - флуорантеном и пиреном. 
Все исследованные мхи характеризуются близким содержанием ПАУ с незначительным увеличением в C. giganteum за счет повышенной доли метилзамещенных соединений. Отношение содержания суммы замещенных нафталинов и фенантренов к содержанию незамещенных ПАУ возрастает от 2,3-2,6 в A. palustre и $W$. fluitans до 4,4 в C. giganteum. Такая особенность состава и содержания ПАУ в $C$. giganteum может быть следствием наличия вблизи его произрастания нефтеносных площадей и поступления из недр растворенных в воде нефтяных компонентов - дополнительного источника проникающих в растение ПАУ.

О наличии в составе органических компонентов C. giganteum южной части Большого Васюганского болота нефтяной составляющей свидетельствует также присутствие в них типичных для нефтяных систем гопанов - норгопана и гопана конфигурации $17 \alpha 21 \beta$ и стереоизомеров гомогопанов $22 \mathrm{~S}$ и $22 \mathrm{R}$ в общей концентрации 0,12 мкг/г, а также диа- и регулярных стеранов $(0,13$ мкг/г). В образце A. palustre эти соединения отсутствуют, а в $W$. fluitans обнаружен только один из них $-17 \alpha 21 \beta$ гопан $(0,01$ мкг/г). Не ясно, как это соединение могло образоваться в $W$. fluitans, поскольку мох был отобран в высокогорном районе вдали от возможных источников загрязнения. Для биологических гопанов характерна $17 \beta 21 \beta$ конфигурация, или наличие в молекулах ненасыщенных связей. Одно из таких соединений - гоп-22(29)-ен (диплоптен) присутствует среди пентациклических терпеноидов во всех исследованных образцах мхов и доминирует в A. palustre и $W$. fluitans, где его концентрация составляет 1,85 и 0,44 мкг/г соответственно. В C. giganteum преобладают пергидропиценовые структуры, представленные олеан-12-ен-3-оном $(0,11$ мкг/г), урс-12-ен-3оном $(0,12$ мкг/г) и урса-9(11),12-диен-3-оном $(0,05$ мкг/г). В целом мхи семейства Амблистегиевых, в отличие от $A$. palustre семейства Аулакомниевых отличаются значительно меньшим общим содержанием пентациклических терпеноидов, особенно диплоптена.

Наряду с пентациклическими, среди циклических изопреноидных структур в исследованных мхах присутствуют бициклические сесквитерпены $\quad(1,1,4 \alpha-$-триметил-5,6-диметилендекагидронафталин в $W$. fluitans и $C$. giganteum и эремофилен в A. palustre), а также стероиды, представленные спиртами и кетонами рядов холестана $\left(\mathrm{C}_{27}\right)$, эргостана $\left(\mathrm{C}_{28}\right)$, стигмастана $\left(\mathrm{C}_{29}\right)$ и циклоартана $\left(\mathrm{C}_{30}\right)$.

Во мхах семейства Амблистегиевых содержание стероидов на порядок превышает содержание пентациклических терпеноидов, в A. palustre это различие не так значительно. В индивидуальном составе A. palustre, в отличие от Амблистегиевых мхов, отсутствуют $\beta$-изомеры холест- и эргостанонов, а также производные эргостана с двумя кетогруппами в молекулах (табл.). Этот мох отличается также пониженным содержанием ацетата стигмастерола и $\beta$-изомера стигмастанона.

Во всех исследованных мхах среди стероидов максимальна концентрация кампестерола $(0,77$ мкг/г в C. giganteum, 1,40 мкг/г в A. palustre, 1,54 мкг/г в W. fluitans), что согласуется с данными [8] о преобладании кампестерола среди стероидов гипновых торфов. Наиболее высокой долей кампестерола в смеси стеролов характеризуется $A$. palustre. В свою очередь $C$. giganteum и $W$. fluitans при одинаковом высоком относительном содержании кампестерола, различаются повышенной долей стигмастерола и ситостерола, соответственно. Как было показано ранее, стигмастерол доминирует среди стеролов в Sphagnum magellanicum [3], а ситостерол является основным стеролом в низинных (древесно-осоковых, древеснотростниковых и др.) торфах Беларуси и Западной Сибири $[9,10]$. Низкое относительное содержание $\mathrm{C}_{29}$ стеролов (стигма- и сито-) в $A$. palustre может являться одним из отличительных признаков мхов семейства Аулакомниевых. C. giganteum отличается преобладанием кетопроизводных стероидов (65\%отн), в $W$. fluitans и A. palustre содержание кетонов и спиртов практически одинаково.

В целом стеролы преобладают среди стероидов во мхах A. palustre и W. fluitans, а в C. giganteum доминируют ненасыщенные соединения с кетогруппой ( $47 \%$ отн). В нем, кроме того, отмечена максимальная среди исследованных мхов относительная концентрация станонов (18\%отн).

Во всех исследованных мхах присутствуют токоферолы, включающие $\alpha-, \beta-, \gamma$ - и $\delta$ - формы, а также ацетат $\alpha$-токоферола, присутствующий только в Амблистегиевых мхах. Основным во всех мхах (93$97 \%$ отн.) является $\alpha$-токоферол. Среди минорных форм в A. palustre повышена концентрация $\beta$-, $\gamma$ и $\delta$-токоферолов, во мхах семейства Амблистегиевых - ацетата $\alpha$-токоферола. В группе Амблистегиевых мхов $C$. giganteum отличается от $W$. fluitans, произраставшего пониженным содержанием $\alpha$-токоферола и его более устойчивого эфира.

C. giganteum отличается от остальных более низкой концентрацией трифенилфосфатов, представленных во всех мхах собственно трифенилфосфатом и набором изомеров его метил- и диметилзамещенных гомологов. В то же время в этом мхе повышено содержание производных фенола (табл.), представленных ванилином и 4-гидрокси-2-метилацетофеноном. 


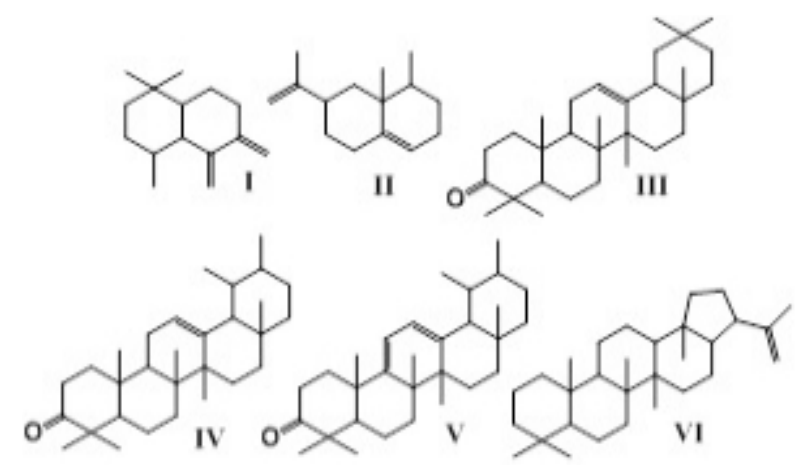

Рис. 1. Структуры циклических терпеноидов, идентифицированных в листостебельных мхах: I - 1,1,4 $\alpha$-триметил-5,6-диметилендекагидронафталин; II - эремофилен; III - олеан-12-ен-3-он; IV - урс-12-ен-3-он; V - урса-9(11),12-диен-3-он; VI - диплоптен

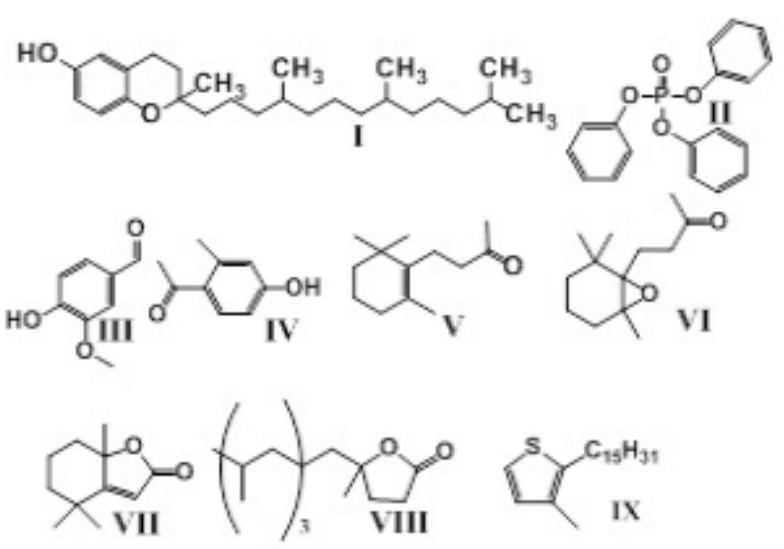

Рис. 2. Строение органических соединений с несколькими функциональными группами, идентифицированных в листостебельных мхах: I - токол; II - 3-фенилфосфат; III - ванилин; IV - 4-гидрокси-2-метилацетофенон; V - $\beta$-ионон, VI - $\beta$-ионон эпоксид; VII - дигидроактинидиолид; VIII - 4,8,12,16-тетраметилгептадекан-4-олид; IX - метил-2-пентадецилтиофен

Минимальным содержанием $\beta$-ионона $(0,01$ мкг/г) и его 5,6-эпоксида $(0,02$ мкг/г) отличается A. palustre. Существенно выше их концентрация в $W$. fluitans (0,07 и 0,16 мкг/г соответственно). Промежуточные значения $(0,02$ и 0,08 мкг/г) зафиксированы в $C$. giganteum. По сравнению со мхами семейства Амблистегиевых в $A$. palustre понижено также содержание производных фурана - дигидроактинидиолида и 4,8,12,16-тетраметилгептадекан-4-олида, а тиофен в A. palustre не обнаружен (табл.).

\section{Выводы}

Состав липидов листостебельных мхов видов A. palustre, C. giganteum и $W$. fluitans характеризуется преобладанием карбоновых кислот и $\boldsymbol{u}$-алканов, в составе которых доминирует гомолог $\mathrm{C}_{27}$. A . palustre отличается от мхов семейства Амблистегиевых пониженным содержанием соединений изопреноидного строения, кетонов, спиртов, $\beta$-ионона и его эпоксида, производных фенола и фурана, отсутствием тиофена, а также повышенным содержанием ненасыщенных кислот, пентациклических терпеноидов и альдегидов, среди которых доминирует нонаналь. В составе стероидов в A. palustre отсутствуют $\beta$-изомеры холести эргостанонов, а также производные эргостана с двумя кетогруппами в молекулах. Среди сесквитерпеноидов в A. palustre был обнаружен эремофилен, отсутствующий в Амблистегиевых мхах.

Внутри семейства Амблистегиевых $W$. fluitans отличается от $C$. giganteum большим содержанием ликопадиена, карбоновых кислот, существенно выше концентрация в нем $\boldsymbol{H}$-алканов, фит-2-ена, альдегидов, эфиров, сквалена, диплоптена, $\alpha$-токоферола и трифенилфосфатов. $C$. giganteum характеризуется преобладанием кетопроизводных стероидов, в $W$. fluitans содержание кетонов и спиртов практически одинаково. Во мхах $W$. fluitans и $A$. Palustre повышено содержание сквалена, диплоптена и стеролов по сравнению c C. giganteum.

\section{Список литературы}

1. Lopez-Dias V., Urbanczyk J., Blanco C.G., Borrego A.G. Biomarkers as paleoclimate proxies in peatlands in coastal high plains in Asturias, N Spain // International Journal of Coal Geology. 2013. Vol. 116-117. Pp. 270-280.

2. Серебренникова О.В., Гулая Е.В., Стрельникова Е.Б., Прейс Ю.И., Дучко М.А. Распределение $н$-алканов, стероидов и тритерпеноидов в торфе и растениях болота Тёмное // Известия Томского политехнического университета. 2013. Т. 323. №1. С. 40-44.

3. Серебренникова О.В., Гулая Е.В., Стрельникова Е.Б., Кадычагов П.Б., Прейс Ю.И., Дучко М.А. Химический состав типичных растений-торфообразователей олиготрофных болот лесной зоны Западной Сибири // Химия растительного сырья. 2014. №1. С. 257-262. 
4. Серебренникова О.В., Гулая Е.В., Стрельникова Е.Б., Кадычагов П.Б., Прейс Ю.И., Дучко М.А. Особенности химического состава растений пресноводного карбонатного озера подтайги Западной Сибири Сибири // Химия растительного сырья. 2014. №3. С. 139-144.

5. Metzger P., Allard B., Casadevall E., Berkaloff C., Coute A. Structure and chemistry of a new chemical race of Botryococcus braunii (chlorophyceae) that produces lycopadiene, a tetraterpenoid hydrocarbon // Journal of Phycology. 1990. Vol. 26. Pp. 258-266.

6. Zhang Z., Metzger P., Sachs J. P. Biomarker evidence for the co-occurrence of three races (A, B and L) of Botryococcus braunii in El Junco Lake, Galapagos // Organic Geochemistry. 2007. Vol. 38. Pp. 1459-1478.

7. Vacha R., Cechmankova J., Skala J. Polycyclic aromatic hydrocarbons in soil and selected plants // Plant soil environment. 2010. N56. Pp. 434-443.

8. Lehtohen K., Ketola M. Solvent extractable lipids of Sphagnum, Bryales and Carex-Bryales peats: content and compositional features vs peat humification // Organic Geochemistry. 1993. Vol. 20. Pp. 363-380.

9. Серебренникова О.В., Стрельникова Е.Б., Аверина Н.Г., Козел Н.В., Дучко М.А. Сравнительный анализ химического состава битуминозных компонентов низинных торфов двух болотных экосистем // Фундаментальные исследования. 2014. №12-1. С. 112-117.

10. Серебренникова О.В., Стрельникова Е.Б., Прейс Ю.И., Дучко М.А. Влияние источника и условий торфонакопления на индивидуальный состав битуминозных компонентов торфа на примере двух низинных болот Западной Сибири // Известия Томского политехнического университета. 2014. Т. 325. №3. С. 80-91.

Поступило в редакцию 10 декабря 2015 г.

После переработки 15 января 2016 г. 
Serebrennikova O.V. ${ }^{1,2}$, Strel'nikova E.B. ${ }^{1}$, Russkih I.V. ${ }^{1}$, Prejs Ju.I. ${ }^{3}$, Duchko M.A. ${ }^{1,2} *$ THE LIPID CHEMICAL COMPOSITION OF LEAFY MOSSES - PEAT-FORMING PLANTS OF EUTROPHIC SWAMPS OF WESTERN SIBERIA AND ALTAI

${ }^{1}$ Institute of Petroleum Chemistry SB RAS, pr. Academic, 4, Tomsk 634055 (Russia), e-mail: maria.duchko@gmail.com

${ }^{2}$ National Research Tomsk Polytechnic University, pr. Lenina, 30, Tomsk 634050 (Russia)

${ }^{3}$ Institute of monitoring of climatic and ecological systems SB RAS, pr. Academic, 10/3, Tomsk 634055 (Russia)

The paper describes the molecular composition of lipids in three samples of leafy moss (Aulacomnium palustre, Warnstorfia fluitans and Calliergon giganteum). Acyclic compounds such as normal and isoprenoid alkanes, isoprenoid alkenes, carboxylic acids and their esters, alcohols, aldehydes, normal and isoprenoid ketones were identified. Cyclic structures comprised of bi-, tri- and tetracyclic polycycloaromatic hydrocarbons (PAHs), bicyclic and pentacyclic terpenoids, steroids and tocopherols were detected. It was shown that carboxylic acids and n-alkanes with the dominance of $\mathrm{C}_{27}$ homologue prevail among the organic compounds identified in mosses. It was found that $A$. palustre is characterized by a reduced content of isoprenoid compounds, alcohols, ketones and high content of unsaturated acids, pentacyclic terpenoids and aldehydes. $A$. palustre also differs from $W$. fluitans and $C$. giganteum in the composition of steroids. The sesquiterpenoid eremophilene was detected in A. palustre, but it is absent in the other mosses. The content of lycopadiene, carboxylic acids, n-alkanes, fit-2-ene, aldehydes, esters, squalene, diploptene, $\alpha$-tocopherol and triphenyl phosphates is higher in $W$. fluitans in comparison to $C$. giganteum.

Keywords: leafy mosses, gas chromatography-mass spectrometry, n-alkanes, oxygen-containing organic compounds, polycycloaromatic hydrocarbons, terpenoids, steroids.

\section{References}

1. Lopez-Dias V., Urbanczyk J., Blanco C.G., Borrego A.G. International Journal of Coal Geology, 2013, vol. 116-117, pp. 270-280.

2. Serebrennikova O.V., Gulaja E.V., Strel'nikova E.B., Prejs Ju.I., Duchko M.A. Izvestija Tomskogo Politehnicheskogo Universiteta, 2013, vol. 323, no. 1, pp. 40-44. (in Russ.).

3. Serebrennikova O.V., Gulaja E.V., Strel'nikova E.B., Kadychagov P.B., Prejs Ju.I., Duchko M.A. Khimija rastitel'nogo syr'ja, 2014, no. 1, pp. 257-262. (in Russ.).

4. Serebrennikova O.V., Gulaja E.V., Strel'nikova E.B., Kadychagov P.B., Prejs Ju.I., Duchko M.A. Khimija rastitel'nogo syr'ja, 2014, no. 3, pp. 139-144. (in Russ.).

5. Metzger P., Allard B., Casadevall E., Berkaloff C., Coute A. Journal of Phycology, 1990, vol. 26, pp. 258-266.

6. Zhang Z., Metzger P., Sachs J.P. Organic Geochemistry, 2007, vol. 38, pp. 1459-1478.

7. Vacha R., Cechmankova J., Skala J. Plant soil environment, 2010, no. 56, pp. 434-443.

8. Lehtohen K., Ketola M. Organic Geochemistry, 1993, vol. 20, pp. 363-380.

9. Serebrennikova O.V., Strel'nikova E.B., Averina N.G., Kozel N.V., Duchko M.A. Fundamental'nye issledovanija, 2014, no. 12-1, pp. 112-117. (in Russ.).

10. Serebrennikova O.V., Strel'nikova E.B., Prejs Ju.I., Duchko M.A. Izvestija Tomskogo Politehnicheskogo Universiteta, 2014, vol. 325, no. 3, pp. 80-91. (in Russ.).

Received December 10, 2015

Revised January 15, 2016

\footnotetext{
* Corresponding author.
} 
